Recherches politiques internationales sur les espaces issus de l'histoire et de la colonisation portugaises

$\mathrm{XV}(1) \mid 2008$

Indiens du Mozambique et d'Afrique orientale

\title{
Guiné-Bissau (1994-2005). Um estudo social das motivações eleitorais num estado frágil
}

Guinea-Bissau (1994-2005). A social study of electoral motivations in a Fragile

State

Guinée-Bissau (1994-2005). Une étude sociale des motivations électorales d'un

État fragile

Carlos Sangreman, Fernando Sousa Júnior, Guilherme Rodrigues

Zeverino e Miguel José de Barros

\section{(2) OpenEdition}

Edição electrónica

URL: http://journals.openedition.org/lusotopie/738

ISSN: 1768-3084

\section{Editora:}

Association des rechercheurs de la revue Lusotopie, Brill, Karthala

Edição impressa

Data de publição: 30 Junho 2008

Paginação: 3-25

ISSN: 1257-0273

Refêrencia eletrónica

Carlos Sangreman, Fernando Sousa Júnior, Guilherme Rodrigues Zeverino e Miguel José de Barros, « Guiné-Bissau (1994-2005). Um estudo social das motivações eleitorais num estado frágil », Lusotopie [Online], XV(1) | 2008, posto online no dia 22 fevereiro 2016, consultado o 30 abril 2019. URL : http:// journals.openedition.org/lusotopie/738 


\section{GUINÉ-BISSAU (1994-2005). UM ESTUDO SOGIAL DAS MOTIVAÇÕES ELEITORAIS NUM ESTADO FRÁGIL*}

Quais foram as razões sociais e políticas da realidade da Guiné-Bissau determinantes no comportamento do eleitorado que levou à presidência da República João Bernardo Vieira « Nino », eleito em 2005 como candidato independente ? O artigo procura relacionar a história desse país da sub-região da África Ocidental - a Senegâmbia - e os objectivos do PAIGC na luta de libertação nacional do colonialismo português de independência, unidade e desenvolvimento, com as motivações de voto em relação a cada um dos candidatos que passaram à segunda volta nas eleições de 1994, 1999 e 2005. As conclusões são elaboradas sob a forma de cenários - retorno, estabilidade, instabilidade controlada e caos suicida - para o futuro próximo.

\section{Guinea-Bissau (1994-2005) \\ A social study of electoral motivations in a Fragile State}

What were the social and political determinants reasons in Guinea-Bissau for the electoral behaviour which elected, in 2005, João Bernardo Vieira "Nino" for President of the Republic as an independent candidate? The article attempts to relate the history of that country in the sub-region of Western Africa - the Senegambia - and the objectives of the struggle for national liberation against the Portuguese colonialism, of independence, unity and development of the PAIGC, with the motivations of voters with regard to each candidate in the second round of the elections of 1994, 1999 and 2005. The conclusions in this research have been drawn up in the form of scenarios - way back, stability, controlled instability and suicidal chaos - for the near future.

\section{Guinée-Bissau (1994-2005)}

Une étude sociale des motivations électorales d'un État fragile

Quelles ont été les raisons sociales et politiques déterminantes, dans la réalité de la Guinée-Bissau, d'un comportement électoral qui a mené à l'élection, en 2005, de João Bernardo Vieira "Nino» à la présidence de la République, comme candidat indépendant? L'article cherche à mettre en relation d'une part l'histoire de ce pays d'Afrique occidentale - la Sénégambie - et les objectifs de la lutte de libération nationale du PAIGC, contre le colonialisme portugais et pour l'indépendance, l'unité et le développement, avec d'autre part les motivations du vote relatives à chacun des candidats du second tour des élections de 1994, 1999 et 2005. Les conclusions sont élaborées en forme de scénarios - retour au passé, stabilité, instabilité contrôlée et chaos suicidaire - pour le futur proche.

$\mathrm{O}$ objecto de análise deste artigo são as motivações do eleitorado guineense na definição do voto nas eleições presidenciais de 1994, 1999 e 2005, que se

* Os documentos de trabalho elaborados pelos autores para este artigo podem ser encontrados em Sangreman et al. (2006). 
realizaram entre vários candidatos, em contexto multipartidário, e depois de um processo de abertura politica que decorreu entre o Congresso do então partido único - Partido Africano da Independência da Guiné e Cabo Verde (PAIGG) - de 1991 e a criação da Comissão Nacional de Eleições em 1993 . Procurou-se também estabelecer alguns cenários da evolução politica guineense decorrentes dos resultados dessas eleições.

Espera-se dar assim um contributo para a compreensão dos processos eleitorais, segundo o modelo « uma pessoa com mais de x anos um voto » em Estados cujo funcionamento institucional não é capaz de proporcionar paz e segurança, boa governação e uma gestão da economia e dos bens públicos de forma a reduzir a pobreza dos seus cidadãos ${ }^{2}$.

\section{A realização de eleições na Guiné-Bissau}

Em 24 de Setembro de 1973, a independência da Guiné-Bissau foi proclamada pelo partido que conduziu a luta armada - Portugal reconheceu essa proclamação em 1974 depois do regime colonialista ter caído - e tem realizado desde então várias eleições legislativas e presidenciais em contexto de tumultuosas transformações políticas, incluindo conflitos envolvendo militares - chegando mesmo a uma guerra civil em 1998-99 : intervenções extra parlamentares de partidos políticos, organizações não governamentais, sindicatos, greves de vários meses de professores, anos de salários em atraso de funcionários públicos e militares, etc., na construção dum processo, segundo Lars Rudebeck, de «democratização difícil » (Rudebeck 2001).

Esses actos eleitorais têm tido taxas de participação de eleitores recenseados ${ }^{3}$ 89,3 \% em 1994, 73,8 \% em 1999 e 87,6 \% em 2005 - muito altas seja qual for o padrão de referência, demonstrando a permanência, em trinta e dois anos de independência, na identidade colectiva da população guineense, da convicção de que o voto é uma acção social que devem assumir. Isso, apesar da deterioração progressiva das estruturas organizativas e da capacidade de mobilização do partido vitorioso na guerra de libertação e partido único no governo até 1991, o PAIGC, como meio de exercício de poder, através de comités de tabanca e de bairro ou organizações regionais, sectoriais de mulheres ou de jovens; e sem existir um processo de substituição dessa presença junto das populações por parte de outros partidos ${ }^{4}$.

Note-se que essas taxas de participação no voto são obtidas num contexto de evolução demográfica ${ }^{5}$ em que $42,9 \%$ das pessoas que podiam votar tinham no

${ }^{1}$ Para as eleições de 1972 e 1976 veja-se como observador externo Chabal, 1983 e 2002 : 124-127. Para uma análise breve das fases de abertura veja-se Kowdawo (1994).

${ }^{2}$ Segundo a noção de Estado Frágil da OCDE, <www.oecd.org/cad/etatsfragiles>.

${ }^{3}$ Segundo a metodologia de cálculo de Rudebeck, 2001: 61.

${ }^{4}$ Koudawo (1994) associa o timing da abertura partidária à deterioração da capacidade organizativa do PAIGC. Ou seja, este autor afirma indirectamente que a população interpretou a abertura partidária em 1991, como uma demonstração do falhanço pelo PAIGC da sua capacidade para liderar a promoção do desenvolvimento.

${ }^{5}$ Os dados deste ponto são retirados de ONU (2004 e 2005) salvo outra indicação. 
máximo cinco anos no ano em que terminou a guerra pela independência e 37,2 \% tinham entre 5 a 24 anos. Com uma esperança média de vida de 44,7 anos, o número de pessoas sem memória directa da época colonial aproxima-se da maioria simples tornando o conjunto dos eleitores guineenses cada vez menos sensível às referencias históricas dos candidatos sobre a sua participação na luta pela independência. A taxa de analfabetismo de 60,4 \% para maiores de 15 anos e um consumo de energia de 41 kws hora, em 2002, quando a média dos países menos desenvolvidos é de 106, são também uma condicionante forte para a compreensão e simples recepção das alternativas que os candidatos propõem.

Se calcularmos um índice simples de funcionamento do sistema eleitoral ${ }^{6}$ verificamos que, comparando com os países da sub-região, ${ }^{7}$ a frequência de realização de eleições em datas previstas na Guiné-Bissau, a partir de 1989, está acima da média juntamente com o Senegal (Tabl. I).

Tabl. I. - Índice de sistema Eleitoral dA sub-REgião, POR DATAS DE INDEPENDÊNGIA E DE ELEIÇÕES MULTIPARTIDÁRIAS (1966-2005)

\begin{tabular}{lrcc}
\hline \multicolumn{1}{c}{$\begin{array}{c}\text { Países - data de } \\
\text { independência }\end{array}$} & $\begin{array}{c}\text { Data de eleiçôes } \\
\text { legislativas } \\
\text { multipartidárias }\end{array}$ & $\begin{array}{c}\text { Índice de sistema } \\
\text { eleitoral } \\
\text { Independência-2004 }\end{array}$ & $\begin{array}{c}\text { Índice de sistema } \\
\text { eleitoral } \\
1989-2004\end{array}$ \\
\hline Gâmbia - 1965 & 6672778287929702 & 89,7 & 66,70 \\
Senegal - 1960 & 8388939801 & 56,8 & 100,00 \\
Guiné-Bissau - 1973 & 949905 & 50,0 & 100,00 \\
Guiné-Conacry - 1958 & 9202 & 21,7 & 66,70 \\
Mali - 1960 & 929702 & 22,7 & 66,70 \\
\hline
\end{tabular}

Fonte: Mozaffar \& Scarritt 2005 para as datas de eleições com excepção da Guiné-Bissau. Metodologia e cálculo do Índice dos autores.

\section{As determinantes do comportamento eleitoral guineense}

As famosas questões que Alain Touraine (1965) colocou na sua análise da acção social - Quem somos? Pelo que lutamos? Contra quem lutamos? - podem servir de ponto de partida para tentarmos entender o comportamento dos eleitores guineenses nas votações presidenciais.

\section{Quem somos? Ou seja, quem são os guineenses na hora de votar?}

A identidade colectiva do país inclui duas componentes históricas que estão presentes de vários modos na sociedade de uma forma mais ou menos clara e influenciam o voto.

\footnotetext{
${ }^{6}$ Seja $\mathrm{N}_{\mathrm{id}}=($ ano $\mathrm{t}-$ ano $\mathrm{k}) / \mathrm{a}_{\mathrm{e}}$ com $\mathrm{a}_{\mathrm{e}}$ a frequência legal no país para realização de eleições, e $\mathrm{t}>\mathrm{k}$; seja $\mathrm{N}_{\mathrm{e}}$ o número de actos eleitorais multipartidários realizados; então ISE ${ }_{(\mathrm{t}-\mathrm{k})}=\mathrm{N}_{\mathrm{e}}$ / $\mathrm{N}_{\text {id }} * 100$. Um indicador deste tipo mede o afastamento em relação a 100 podendo ser inferior, igual ou superior.

${ }^{7}$ Para outros países veja-se CARBone 2005, e as fontes que refere.
} 
A primeira que referiremos como a componente de longo prazo, tem a ver com a formação do espaço kaabunké. A invasão fula que levou ao fim do Reino Mandinga do Gabu em 1867 (Niane 1989 ; Pélissier 2001 ; Lopes 1987, 1999) e a divisão do território na fronteira Norte que passou a considerar Casamance como parte do Senegal, em 1886, estão ainda suficientemente presentes na memória colectiva, para que as clivagens entre vencidos e vencedores tenham peso na hora de votar. Como afirma Carlos Lopes (1999),

«O Kaabú [...], resulta de uma herança de séculos e não de uma dezena de anos, é um elemento fundamental para interpretar as interacções dos diferentes grupos (étnicos, sociais, classes) na Guiné-Bissau, Gâmbia e Casamance. » (1999 : 240)

Nóbrega (2005) escreve que Ansumane Mané, enquanto chefe militar vitorioso, depois da guerra civil de 1998-99 não visitou nem uma única tabanca fula, querendo assim dizer que a derrota dos mandinga e dos seus aliados estava ainda presente na sua memória.

Igualmente as acções que visem ajudar as pessoas do outro lado da fronteira são objecto de um consenso social que ultrapassa a lógica da formação das relações entre Estados e atravessa vários níveis sociais desde os vizinhos da mesma etnia até ao apoio de partidos e governantes guineenses aos movimentos que reivindicam a separação do Senegal ${ }^{8}$. Do mesmo modo na guerra civil guineense esses combatentes vieram ao país lutar ao lado dos militares da Junta chefiada por Ansumane Mané contra a tropa senegalesa e da Guiné Conacry. Não encontramos, no período considerado neste artigo, um único partido ou candidato presidencial que tenha um discurso de negação explicita desse apoio, que sobretudo em toda a zona norte lhe tiraria votos.

A segunda componente de médio prazo da identidade guineense tem a ver com a unidade das etnias na formação da Nação guineense a partir da luta armada dirigida pelo PAIGC contra o regime colonial. Note-se que o oficial português Teixeira Pinto, tendo um chefe mercenário fula senegalês, Abdul Injai, como aliado, consegue ocupar todo o território em quatro campanhas entre 1913 e 1915, sem defrontar nenhuma coligação das etnias presentes mas sempre fazendo alianças e explorando as rivalidades existentes entre grupos ${ }^{9}$.

O PAIGC, exerceu a liderança da luta pela independência elegendo três objectivos de síntese de mobilização da população : a independência, o desenvolvimento, e a unidade de todos os que viviam no território. Desses objectivos, o terceiro remete directamente para a identidade nacional. Em 1969, Amílcar Cabral considerava que :

«...qualquer que seja o grupo étnico a que pertençam foi fácil levar as pessoas a considerar que somos um povo, uma nação [...] o que entre nós subsistia de tribalismo foi destruído pela luta armada que conduzimos. [...] Só os oportunistas políticos são tribalistas. » (1974 : 70-71)

\footnotetext{
${ }^{8}$ Veja-se o mapa das etnias da zona da Senegâmbia de CARreIra 1969 onde se regista a existência de felupes, mandingas e fulas dum e doutro lado da actual fronteira.

9 PÉlissier (2001) regista cerca de 72 campanhas, recontros, escaramuças só entre 1850 e 1920. Nota igualmente (p. 410) que os portugueses não travaram nem uma só batalha significativa contra uma aliança de vários grupos étnicos, mas sempre contra grupos isolados.
} 
Note-se que outros membros da direcção do PAIGG não tinham a mesma visão do efeito da luta de libertação nas clivagens étnicas. Manuel dos Santos afirmava :

«A luta armada de libertação nacional [...] criou importantes laços de solidariedade e interdependência entre os diferentes grupos, mas [...] não realizou a unidade nacional, nem engendrou a Nação guineense. Construiu, sim, as suas bases, os seus fundamentos, os alicerces da Nação e criou as condições necessárias mas não suficientes ao seu aparecimento. » (1989: 194-195)

Mas seja qual for a posição assumida pelos dirigentes, na luta e na construção da Nação e do Estado guineense, todos consideram as clivagens de origem étnica como inimigas desse processo. Tal componente estrutural influencia necessariamente o comportamento eleitoral dos guineenses e os candidatos à presidência afirmaram a necessidade dessa união em vários momentos da campanha eleitoral.

No entanto, nas entrevistas realizadas, o raciocínio da motivação étnica do voto está sempre presente nas previsões e nas análises dos resultados. Dos partidos com mais votos nas eleições legislativas, o termo de «partido balanta » aplicado ao Partido da Renovação Social (PRS) é uma designação generalizada, e apenas o PAIGG surge como a formação que se dirige a todas as etnias, a par de alguns dos partidos constituídos por quadros urbanos como a União para a Mudança (UM) e o Partido Unido Social Democrata (PUSD).

Uma metodologia possível para tentarmos perceber até que ponto essa componente de unidade tem importância na vida politica do país é olhar para os elementos recentes que podem mais claramente ser a expressão da divisão entre guineenses : os conflitos envolvendo militares e os resultados das eleições de acordo com as etnias presentes ${ }^{10}$.

Vamos considerar apenas os conflitos recentes, sem esquecer que seja 1961, quando Amílcar Cabral tentou unir o seu partido com a União dos Povos da Guiné liderada por Henry Labery e o Movimento de Libertação da Guiné de François Mendy Kankoila, seja em 1964, no I ${ }^{\circ}$ Congresso do PAIGC em Cassacá11, os conflitos presentes tiveram a ver com a unidade entre a Guiné e Cabo Verde e com a oposição entre os que concebiam o Partido como um instrumento de libertação do povo guineense, e os que estavam predispostos a servir-se do partido para a construção de poder pessoal. Ainda hoje se pode detectar nos discursos de candidatos a eleições referencias a esses conflitos. Mas as memórias das pessoas que estiveram na luta, apenas salientam o maior empenho no combate dos balantas

${ }^{10}$ Embora com a consciência que, como nenhum partido se reclama do voto étnico, tal análise permite tirar somente conclusões indicativas.

11 Para além do próprio Amílcar Cabral, muitos autores académicos, políticos e jornalistas guineenses e não guineenses escreveram sobre o congresso de Cassacá; Carlos Lopes e Carlos Cardoso académicos guineenses, Luís Cabral político guineense, Basil Davidson, Patrick Chabal, Rosemary Gally e António Nóbrega académicos não guineenses têm, quanto a nós, os textos mais interessantes. Mas ficamos com a convicção que ainda está muita coisa para contar. Quando se fala deste Congresso com os entrevistados referidos nas fontes deste artigo as interpretações e as informações variam de pessoa para pessoa, acentuando essa convicção. Uma fonte ainda não acessível - os cadernos de notas de Vasco Cabral - poderiam trazer mais alguma luz ao assunto. 
em relação a outros grupos étnicos, e a capacidade militar de comandantes e combatentes de diferentes etnias como Nino (papel e único comandante de frente de combate inicial sobrevivente), Iafai Camará (fula) ou Ansumane Mané «Brik Brak » (mandinga), afirmando sempre que não havia manifestações de divisão étnica.

Essa memória é confirmada pelo Recenseamento dos antigos combatentes ainda vivos em 2000-2001, feito nessa data para o projecto PDRRI ${ }^{12}$, pelos próprios combatentes, e onde se pode verificar a mistura de etnias nas forças armadas da luta $^{13}$. Já em 1986, quando sessenta e três ${ }^{14}$ pessoas são presas acusadas de conspiração, e seis, todos militares ou ex-militares - entre os quais o ex-Vice-Presidente do Conselho de Estado, Paulo Correia e o ex-Procurador Geral, Viriato Pã -, são fuzilados, as poucas análises existentes notam o peso de balanta de prestígio entre os acusados ${ }^{15}$. Nóbrega (2005) diz mesmo que os balanta deixaram de estar nas manifestações de apoio a Nino considerando que a acusação de conspiração se estendia à sua etnia.

O conflito mais grave - a guerra civil de 1998 e $1999^{16}$ - teve origem imediata na revolta do então Chefe do Estado Maior, Ansumane Mané, mandinga da Gambia, reagindo a uma tentativa de Nino de alterar o tipo de apoio dado ao movimento de Casamance, por pressão politica do Senegal e internacional. A origem mais remota tem a ver com os conflitos internos do PAIGC e as diferentes condições de vida dos militares de baixa e alta graduação ${ }^{17}$ que não cabe aqui desenvolver. A direcção desse conflito, a Junta Militar, foi composta inicialmente por militares de etnias diferentes e vários, senão todos, com larga experiência em combate na guerra de libertação, ${ }^{18}$ tal como os militares que se mantiveram fiéis

12 Projecto de Desmobilização, Reinserção e Reintegração dos ex-Combatentes, financiado pelo Banco Mundial e por vários governos como o sueco, holandês e português.

${ }_{13}$ Ministério do Trabalho e Solidariedade (MTS) 2001.

${ }^{14}$ Induta (2001) inclui listas pormenorizadas dos oficiais detidos e respectivos postos.

${ }^{15} \mathrm{O}$ dossier publicado pelo jornal Baguera, no 5, de Julho de 1993 ainda se mantém a melhor fonte para este conflito.

${ }^{16}$ Temos hoje algumas obras que relatam e analisam o que se passou, embora ainda haja muito pouca divulgação sobre a morte de Ansumane Mané e nenhuma obra com origem em autores senegaleses, Guiné-Conacry ou França, partes participantes. São de salientar a recolha de notícias nos média portugueses feitas pela AcEP (2000), o livro de Zamora Induta (2001), o de Lars Rudebeck (2001), antecedido por um artigo na Lusotopie (1998), a tese de mestrado de Guilherme Zeverino (2005), o número especial com vários autores da revista Soronda sobre o conflito, a narrativa de Roy VAN DER DRIFT sobretudo da sua própria experiência em teatro de guerra publicado na Lusotopie (1999) e o livro de Alexandre Reis Rodrigues \& Américo Silva SANTOS (2007) sobre a acção das forças armadas portuguesas no conflito a partir de fontes militares e diplomáticas envolvidas na acção.

17 O livro de Filinto de Barros, Kikia Matcho, Lisboa, Editora Caminho, escrito em 1997, é um romance premonitório que parte de uma análise muito boa da situação contraditória a que chegaram os antigos combatentes, e da conviçção, algo mágica e confusa, que se vai instalando na consciência colectiva dos mesmos de que é preciso fazer alguma coisa para mudar.

${ }^{18}$ Curiosamente não é fácil saber quem eram os membros da Junta dado o carácter um tanto informal das suas reuniões. Consultando os nomes que surgem nas delegações da Junta em diferentes ocasiões e a memória dos entrevistados, os militares iniciais que comporiam o chamado Comando Supremo seriam, além de Ansumane Mané, mandinga; Melcíades Fernandes (vulgo 
ao Presidente. A entrada na guerra de tropas do Senegal e da Guiné-Conacry teve como efeito fazer surgir de novo na população o sentimento de luta contra um invasor, transformando o conflito até aí entre militares guineenses numa nova «luta de libertação » unificadora de todas as etnias. Mesmo assim a excepção foi, no final da mesma, o recrutamento por parte de Nino, de milícias papel, os « aguenta », para tentar manter-se no poder.

A conclusão que podemos tirar desta componente da vida politica guineense é que não nos parece ser claro que haja um peso grande de alguma divisão étnica nos conflitos armados registados. A pertença étnica está presente, mas os conflitos eclodem ou extinguem-se com recurso limitado e esse dado. Portanto o voto eleitoral que derive de motivações a favor ou contra os participantes nesses conflitos não tem relação significativa com as etnias dos mesmos.

A relação da motivação para o voto com os conflitos exprime-se mais na necessidade da paz afirmada pelos candidatos na campanha e por todos os entrevistados.

Se utilizarmos a comparação entre os resultados eleitorais por região e a distribuição geográfica das etnias, tendo como fonte de mapas o trabalho de Nóbrega (2005) que tem a distribuição étnica da população com base nos mapas de Carreira (1969), na tese de licenciatura de Braga Dias em 1974 e no Recenseamento da Guiné-Bissau de 1991, detecta-se para as legislativas de 1999, uma clara correlação entre as regiões de maior presença de população balanta e o voto no PRS de Koumba Yalá ${ }^{19}$. Se olharmos para os resultados das presidenciais constantes nos anexos I e II, vemos que em 1994, Koumba Yalá ganha contra Nino Vieira em todas as regiões onde a maioria é balanta excepto em Quinara, no Sul e ainda ganha também em chão manjaco e Bissau; em 1999 ganha contra Malam Bacai Sanha em todas as regiões do país seja qual for a etnia maioritária. Faustino Imbali (2005) também balanta, faz uma análise da acção de Koumba Yalá na campanha de 1994 afirmando : «Ele fez apelo ao sentimento de solidariedade dos balanta, enaltecendo o sofrimento ligado a episódios violentos que marcaram a história do país, e designando à vindicta um grupo de pessoas. »

Nino Vieira tem, em 1994 e 2005, a maioria absoluta em Biombo, chão papel, sendo legitimo concluir ter tido um voto de motivações étnicas nessa região. Mas a verdade é que o mesmo sucede na região de Bolama onde o predomínio é da etnia bijagó. Em 2005, como independente contra Malam Bacai Sanha (apoiado pelo PAIGC), vence claramente apenas em Bolama e Biombo, perdendo ou ganhando nas restantes, mas ficando muito perto do seu adversário, mesmo nas regiões de maioria balanta e mandinga.

Malam Bacai Sanha perde em todas regiões para Koumba Yalá em 1994 e ganha ou perde por poucos votos contra Nino Vieira, em 2005, também em todas as regiões.

Manel Mina), papel e caboverdiano ; Iaia Cany, fula ; Emilio Costa, balanta ; Zamora Induta, balanta; Mohamad Lamine Sanha, mandinga; Bubo Na N'tchut, balanta; Buota Na M'batcha, balanta; Veríssimo Seabra, papel e caboverdiano e Baba Djassy, beafada. Vários civis como Francisco Benante, Francisco Fadul, Manuel Barcelos, Silvestre Alves e outros juntaram-se à Junta como conselheiros mas não sabemos até que ponto o seu papel foi determinante e se tinham ou não assento permanente em todas as reuniões.

19 Adopta-se aqui a forma de escrever o nome do ex-presidente que ele próprio utiliza nos seus escritos, YALÁ 2003. 
O que se pode concluir destes resultados é a existência de motivação étnica para o voto em relação a Nino Vieira na região de Biombo, seja qual for a situação politica de acontecimentos relacionados com o candidato. Na eleição de 1999 onde Nino não concorreu, o Biombo votou Koumba Yalá e não Malam Bacai Sanha, um beafada apoiado pelo PAIGC, talvez votando contra o candidato que surgiu em todo o processo como tendo contribuído mais para a derrota de Nino na guerra civil $^{20}$. Os Bijagós dividem-se mais, não se podendo afirmar que a motivação é étnica.

Igualmente o voto em Koumba Yalá pode-se considerar étnico nas eleições de 1994 mas não nas de 1999. Em relação a Malam Bacai Sanha não pensamos poder atribuir à motivação étnica os votos que recebeu ou não em nenhuma das regiões. Sendo o único candidato islamizado nem no somatório das duas regiões Bafatá e Gabú - com maioria de população muçulmana conseguiu vencer em nenhuma das eleições.

Como conclusão pensamos que não se pode fazer uma análise simplista dos resultados baseados em dados parciais das etnias dominantes nas diversas regiões. Uma análise mais pormenorizada leva à conclusão que a motivação étnica existe localizada como determinante só no Biombo em relação a Nino Vieira - mas não é determinante na motivação da maioria do eleitorado.

\section{Pelo que lutamos? Ou seja, que querem os guineenses quando votam?}

Depois de vermos o objectivo de «unidade» tomemos neste ponto os restantes independência e desenvolvimento - para percebermos se podemos considerar que são significativos no processo de decisão de voto mais de vinte anos depois de 1973.

A independência para o PAIGC sempre foi um objectivo de luta equiparado ao fim do domínio colonial. A mudança de poder político no golpe de Estado de 1980, tem hoje a interpretação consensual de ter sido o reajuste do poder conquistado na independência, para atribuir mais poder aos dirigentes guineenses em detrimento dos caboverdianos. Julgamos portanto que a participação na luta de libertação é um critério importante a favor dos candidatos que o fizeram, mas o seu peso tende a esbater-se nas gerações mais novas.

Os candidatos que atingiram a segunda volta das eleições presidenciais participaram na luta, mas apenas Nino tem a aura de combatente mítico, tendo sido comandante de frente. Quem recolha testemunhos de militares portugueses que combateram na Guiné ouvirá dizer que «quando eles se aproximavam do arame farpado já sabíamos que quem comandava era Nino ». Koudawo afirma mesmo que o candidato na campanha utilizou o seu nome de guerra dado pelos balanta Kabi $\mathcal{N a}$ Fantchamna -, e a exposição da sua vida pessoal para recordar aos eleitores que ele é que era o «continuador da obra de Amílcar Cabral : a afirmação da dignidade do guineense, a fundação da sua nacionalidade, a unidade nacional num país multicultural, multi-étnico, e até multirracial» (Koudawo 1994: 22)21.

${ }^{20}$ Malam Bacai Sanhá num discurso em 2005 afirma ao desafiar Nino para um debate na televisão: «Hoje acusam-me de ser eu quem preparou a guerra », Diário de Bissau, Junho de 2005.

${ }^{21}$ Koudewo faz neste texto uma análise muito pormenorizada das diferentes formas como os diversos candidatos presidenciais na primeira e segunda volta se posicionaram face à história da luta pela independência. 
Na guerra de 1998-99, a intervenção senegalesa e guineense (Conacry) poderia ter criado uma nova importância eleitoral do objectivo de independência nacional e denegrido a imagem popular de Nino Vieira. Mas a vitória militar sobre as forças estrangeiras apenas reforçou a identidade guineense, diminuindo o peso político negativo que o então presidente poderia carregar por ter chamado em seu socorro os exércitos vizinhos. Pelos comunicados ou pelas posições públicas assumidas pela Junta Militar durante a guerra, em nenhum momento os dirigentes consideraram a possibilidade de serem derrotados militarmente ${ }^{22}$.

$\mathrm{O}$ efeito social visível foi a retoma de prestigio social dos antigos combatentes e mesmo de guineenses que tinham lutado como «comandos» ao lado dos portugueses e lutaram agora contra os senegaleses e guineenses de Conacry, pois quando a guerra se generalizou em Bissau, eram esses combatentes que sabiam lutar e as gerações mais novas viram com os seus olhos que as histórias contadas por eles não eram imaginadas ${ }^{23}$.

Com tal desfecho da guerra civil o objectivo da independência não teve grande projecção no discurso dos candidatos e não nos parece que tenha influenciado a motivação de voto. O objectivo que nos parece decisivo para as escolhas eleitorais na definição daquilo «por que lutamos » é o desenvolvimento.

As promessas de alcance de níveis de vida melhores foram uma constante nos textos de Amílcar Cabral, bem como nos discursos de todos os níveis de poder depois da independência. O balanço dos três anos de independência (Moita \& Pereira 1976) após uma visita ao país com múltiplos contactos, é bem significativo da expectativa da população em geral e dos militantes do PAIGC em particular, de conseguirem proporcionar a si e aos seus descendentes o acesso a bens de consumo privado e a bens públicos que não tinham conseguido antes no tempo colonial.

O percurso económico do país está intimamente relacionado com as opções políticas e sociais que foram sendo tomadas ao longo destas três décadas (Cardoso 1995, 2002). As principais riquezas naturais da Guiné-Bissau provêm essencialmente das pescas e florestas e dos recursos minerais (fosfatos, bauxite e depósitos ainda não explorados de petróleo). Em 2003, a população activa vivia maioritariamente da agricultura (82\%), $4 \%$ afecta à indústria e $14 \%$ aos serviços, em particular administração pública central. A produção mantinha-se entre $43 \%$ e $48 \%$ do sector agrícola e pescas, destinada sobretudo ao auto-consumo (Sangreman 2003).

Para além da baixa produtividade, a inexistência de vias de acesso dificulta que algumas regiões, nomeadamente as do Sul ou as Ilhas do arquipélago dos Bijagós, consigam comercializar os seus bens. Esta dificuldade é ainda mais agravada durante a época das chuvas.

Em 1986, a delegação do Banco Mundial chegada a Bissau nas vésperas do Congresso do PAIGC apresentou um Programa de ajustamento económico (PAE) a médio e longo prazo, com uma fase de estabilização (1987-1989) e uma fase

${ }^{22}$ Consulte-se Induta (2001) ou a colectânea de notícias, textos e artigos que a AcEP (2000) reuniu durante a guerra.

${ }^{23}$ Vejam-se a colectânea referida na nota anterior, onde se descrevem as lutas de Bissau, a tomada de Mansôa, de Bafatá, a luta onde morreu o comandante das tropas da Guiné-Conacry, etc. 
de ajustamento nos anos seguintes. Este programa levou à perda da independência no processo de definição da política económica e social que passou a reger-se pelos acordos com as organizações internacionais. O Congresso do PAIGC de finais de 1986 aceitou essa situação ao não deliberar sobre opções de planificação como tinha feito nos anteriores (Sangreman 2003; Koudawo 2001). Pretendia-se a redução do papel do Estado, a liberalização dos preços, o fim do monopólio estatal nas actividades comerciais, e a racionalização do investimento do Estado, com reestruturação e privatização do sector empresarial público. Porém, a canalização dos financiamentos externos para sectores onde se verificava a «apropriação » por parte da classe burocrática do Estado teve como resultado a deterioração da capacidade de investimento das empresas (Cardoso 2002).

Esta estratégia culminou, em 1997, na adesão à União Económica e Monetária da África Ocidental (UEMOA), visando uma maior estabilidade cambial e melhor integração no mercado daquela região, desaparecendo a então moeda nacional, o peso guineense, substituído pelo franco CFA.

De 1988 a 1993 a inflação manteve-se igual à desvalorização, não se conseguindo diminuir as importações nem tão-pouco estimular as exportações (Monteiro 1996). Para o período posterior à entrada na UEMOA em média o Banco Mundial estima uma inflação de $2 \%$ com os salários médios de 48,85 € por mês.

Entre 1987 e 1992, a dívida externa da Guiné-Bissau aumentou de 473 milhões de dólares para 631 milhões, dados os diversos reescalonamentos por falta de pagamento. De acordo com Van Maanen o país tinha uma dívida de mais de $3000 \%$ da receita da exportação prevista. (Monteiro 1996).

No período entre 1990 e 1998 a evolução do PIB foi igual a -3,4\% \%, ou seja houve uma diminuição da riqueza produzida. Coerentemente entre 1991 e 2001 verificou-se que a pobreza absoluta (rendimento inferior a $2 \$$ por dia) passou de $49,0 \%$ para $64,7 \%$, sendo que fora de Bissau representava 69,1 \% da população (Onu 2004).

Se estes indicadores quantitativos macroeconómicos forem complementados com indicadores qualitativos mais ligados ao dia a dia da população teremos uma análise com algumas contradições. Quem viu Bissau em 1986 e voltou a ver vinte anos depois pode constatar uma melhoria geral ao longo de todo esse período. Com efeito, era normal encontrar pessoas de todas as idades descalças na rua, com roupa de má qualidade ou em estado avançado de degradação. Tal situação vai desaparecendo. Já em 1994 notámos que as pessoas nessas condições tinham passado a ser tratadas pela população como indigentes ou doentes mentais.

Referindo-nos aos inquéritos aos orçamentos das famílias de 1986 e 1994 podese comparar a forma como são respondidas as questões sobre despesas em vestuário. Em 1986 não surgem diferenças nas despesas entre roupa usada ou nova. Nessa altura os fardos de roupa ofertados ao país como ajuda externa encontravam-se à venda no mercado e era aí que uma boa parte da população parecia vestir-se, para além do uso dos panos tradicionais (Sangreman 2003). É evidente que os familiares dos altos quadros do Estado e de empresas públicas apareciam com roupas europeias ou com a balalaica de inspiração russa.

Em 1994, nos boletins de inquérito, surgem referências expressas à compra de vestuário usado, separado da compra de roupas novas. Ou seja, as despesas com roupa usada ou nova passaram a ser claramente separadas, como sintoma de um 
mercado de roupa nova, acessível a grupos da população mais alargados. E em 2000 havia já lojas em Bissau que só vendiam roupas europeias.

O estado geral dos taxis em 1986 era de «ruínas ambulantes » com portas presas por arames, arranque de «empurrão », pinturas de anos, e em número relativamente pequeno. Em 2004 um carro nessas condições nem tem clientes, pois os restantes têm em geral bastantes anos mas andam em bom estado ${ }^{24}$.

$\mathrm{O}$ número de cabeleireiras (só feminino ou misto) e o aspecto das raparigas e mulheres no sentido de arranjo de cabelo, adornos, roupa, ou o aspecto exterior mais cuidado das pinturas e arranjo de casas particulares, com recipientes com flores, a substituição das coberturas das habitações mais pobres de palha por chapas de zinco, são igualmente indícios que contribuem para a ideia de que houve uma melhoria geral do bem-estar da população a partir de 1986 .

Mas, mesmo com essas indicações contraditórias, vários dos entrevistados salientam que a «geração da luta de libertação » não foi capaz de corresponder às expectativas da população e desenvolver o país.

Deste modo, no discurso dos candidatos à presidência podemos constatar como o tema «desenvolvimento » está sempre presente. Malam Bacai Sanhá desenvolve o tema em várias vertentes económicas e sociais, apoiando-se no programa do PAIGG e defendendo que a sua geração «não devia falhar outra vez » em «o início duma caminhada que visa levar a Guiné-Bissau ao lugar onde havia sido posta pelo mundo, perante o concerto das nações, virado para o desenvolvimento » (discurso de início de campanha em Gabu). Ou

«O meu inimigo é o $\mathrm{HIV} /$ sida, a tuberculose e o paludismo que todos os anos ceifam a vida de milhares de crianças e jovens. O meu inimigo é o atraso económico, tecnológico e científico desta terra. O meu inimigo é a pobreza que impede o nosso povo de progredir, de ser feliz e de tomar parte nos enormes progressos que marcam a marcha da humanidade neste dealbar do milénio. O meu combate, o combate para o qual convido todos os guineenses, a partir do dia 25 de Julho próximo realizarmos o sonho de ver as nossas crianças a viverem num país sem fome, sem sangue, sem ódio ; num país de justiça, de igualdade, preenchidos de oportunidades e de realizações ; num país iluminado, conectado, extravasado de negócios ; uma Guiné próspera, em que os melhores serão devidamente reconhecidos e recompensados e os mais de carência apoiados. $»^{25}$

Mesmo candidatos com menor projecção como Adelino Mano Queta apresentamse como «o candidato capaz de garantir água potável e saúde à população, bem como educação de qualidade para as nossas crianças e jovens » (discurso em Mansôa, Nố Pintcha 2005), centrando os discursos ao longo da campanha na necessidade de aproveitar «as riquezas do país».

Nino Vieira em qualquer das campanhas onde se candidatou utilizou sempre a ideia que só ele era capaz de conseguir condições para assegurar o desenvolvimento. Mesmo em 2005, como candidato independente, nunca deixou de fazer

${ }^{24}$ São aliás «beneficiários » das disposições legais europeias que impedem a circulação de carros acima de uma dada idade ou quilometragem nas estradas da Europa, mas não a sua exportação para África.

${ }^{25}$ Malam Bacai, 20 de Julho 2005, <www.africanidades.blogger.com.br/2005_07_01_archive. html>. 
alguma confusão entre o seu programa e o do PAIGG nesta e noutras matérias de apelo ao voto ${ }^{26}$.

$\mathrm{O}$ falhanço do objectivo genérico do desenvolvimento, sentido por qualquer elemento da população face ao acesso a bens de consumo corrente, estado da saúde, educação, estradas, etc., torna-se um dos principais critérios de escolha de partidos ou candidatos presidenciais.

\section{Contra quem lutamos? Ou seja, quem são os adversários para os candidatos?}

Os candidatos à presidência não identificam claramente um inimigo que possa servir de motivação para captação de votos num processo de defesa contra uma ameaça personalizada. Cada candidato luta contra quem acha que não é capaz de assegurar a unidade, a paz e o progresso/desenvolvimento tão bem como eles, ainda de acordo com a cultura política das eleições antes da independência quando as votações se faziam em candidatos propostos pelo PAIGC, não havendo durante a luta, perspectiva de disputa eleitoral entre partidos ou entre candidatos individuais (Cabral 1974) tal como se processa na actualidade.

Mesmo Koumba Yalá, nos seus discursos de campanha conhecidos, procurava termos vagos para atribuir as culpas do estado do país. Imbali (2005) diz que a designação « eles » como « inimigos dos balantas » é um exemplo da identificação não personalizada dos adversários nessa campanha e foi sistemáticamente utilizada para «identificar com tudo e todos ».

Candidatos com menos possibilidades de ganharem ou nunca referem adversários (Adelino Mano Queta) ou referem apenas os três com maiores hipóteses de receberem votos, como fizeram Francisco Fadul ou por diversas vezes Idrissa Djaló, que a imprensa guineense referia como sendo aquele que era a excepção na « moderação verbal » da campanha. Quando as campanhas se aproximam do fim todos os candidatos em geral quebram estas regras não escritas, para se acusarem mutuamente de corrupção, roubo, negócios ilícitos, oportunismo pessoal, etc., como a imprensa local notícia. Não nos parece portanto um elemento importante do discurso eleitoral nem da motivação de voto.

\section{Os cenários do futuro próximo}

Neste ponto vamos tentar compreender os resultados das eleições de 2005 através do fenómeno do deslocamento de votos e esboçar cenários futuros a partir de quatro hipóteses sobre a evolução da situação política, partindo dos elementos de base da composição etária, da instrução da população e da manutenção de uma alta taxa de participação em eleições no contexto de desenvolvimento e de conflitos que procurámos esboçar.

Note-se que não há em nenhuma das eleições sondagens credíveis. O ensaio da introdução deste tipo de métodos foi realizado nas eleições legislativas de 2005 :

${ }^{26}$ Vejam-se os jornais das respectivas épocas. 
- o site <www.guine-bissau.net> apresentou uma votação on line das legislativas de 2005, mantendo-se à frente as quatro formações que as entrevistas que realizámos também referiam (PAIGC, PUSD, PRS e Plataforma Unida);

- a Comissão Nacional de Eleições encomendou a uma empresa brasileira uma sondagem em todo o país. Ignoramos a metodologia, mas os resultados divulgados por comunicado daquela Comissão, apontaram, para 37184 inquiridos, uma vitória do PUSD (41,2 \%), seguido pelo PAIGC (26,7), PRS (13,2 \%), Plataforma Unida (4,7 \%), Outros com 2,5\% e com 11,7\% de indecisos.

Vejam-se os resultados para se poder concluir que as respostas a este tipo de pergunta não fazem parte da cultura do país, dando resultados que têm pouco que ver com os finais.

A volatilidade nas eleições presidenciais na Guiné-Bissau, seguindo a metodologia de Pedersen (1979), é um índice que procura quantificar o conceito do deslocamento de votos entre partidos em diferentes eleições. Ou seja, procura medir a fidelidade do eleitorado, expressando numa escala as variações de percentagem de votos conseguida por cada formação partidária. Os autores que conhecemos ${ }^{27}$ calcularam este índice para eleições legislativas, tendo determinado em geral uma mais baixa volatilidade dos Estados europeus e da América do Norte com sistemas eleitorais estabilizados e uma mais alta volatilidade nos países em desenvolvimento da América Latina ou dos países de Leste ex-URSS. Para a África Subsariana, Kuenzi \& Lambright (2001) calcularam uma volatilidade média para trinta países africanos de 28 \% com vários países a atingir 50 \%. Mozaffar \& Scarritt (2005) quatro anos depois para 91 actos eleitorais encontraram uma média de volatilidade eleitoral de 30,07 \% e Carbone (2005) refere 31,3\% para uma amostra mais restrita.

Neste artigo procurámos aplicar esse conceito às eleições presidenciais tomando os candidatos comuns a mais de uma eleição (Tabl. II). As conclusões que podemos tirar são de uma volatilidade baixa, quando comparada com o mesmo indicador para eleições legislativas, das médias referidas. Mas também uma subida de 1994 para 1999 e deste ano para 2005, revelando uma procura de voto por parte dos eleitores com diminuição da fidelidade aos candidatos.

$\mathrm{Na}$ segunda volta - portanto só com dois candidatos em cada acto eleitoral ${ }^{28}$-, é de realçar os dados das regiões com maiores variações como:

- Bolama e Biombo, onde o comportamento eleitoral estabiliza o voto no candidato Malam Bacai Sanhá (1999 e 2005) e desloca-se para o outro candidato seja ele Koumba Yala ou Nino Vieira, favorecendo este último se a escolha for entre os dois ;

- Bissau, onde Nino Vieira tem uma percentagem relativamente estável mas perdendo sempre por pequena diferença para o outro candidato.

\footnotetext{
${ }^{27}$ Veja-se Ferree (2005) e fontes citadas.

${ }^{28}$ Este indicador na prática transmite a informação da mudança de voto para cada um dos três candidatos que disputaram a segunda volta em 1994 (Nino Vieira e Koumba Yalá) em 1999 (Malam Bacai Sanhá e Koumba Yalá) e 2005 (Nino Vieira e Malam Bacai Sanhá), uma vez que em nenhum caso passaram os mesmos, mas sim diferentes combinações dois a dois dos três candidatos.
} 
Pode-se ainda afirmar que as regiões onde os candidatos podem esperar menor variação de comportamento eleitoral são o Oio, Tombali e Quínara. As regiões de Bafatá e Gabú, com maior predominância das etnias Fula, têm, no conjunto dos actos eleitorais, um comportamento de variação média.

Tabl. II. - ÍNDiGes DE VOlatilidAdE NAGIONAL NA PRIMEIRA VOLTA E POR REGIÕES NA SEGUNDA VOLTA

\begin{tabular}{lccc}
\hline \multicolumn{1}{c}{ Área/ periodos eleitorais } & $1994 / 1999$ & $1994 / 2005$ & $1999 / 2005$ \\
\hline Nacional & 9,4 & 11,0 & 20,1 \\
Tombali & 5,7 & 6,5 & 6,2 \\
Quínara & 5,0 & 9,8 & 6,5 \\
Oio & 2,1 & 4,2 & 9,8 \\
Biombo & 33,5 & 7,0 & 1,6 \\
Bolama & 30,2 & 11,7 & 0,1 \\
Bafatá & 9,7 & 16,0 & 6,6 \\
Gabu & 16,8 & 5,8 & 9,5 \\
Cacheu & 12,7 & 3,6 & 18,7 \\
Bissau & 11,3 & 1,5 & 13,0 \\
\hline
\end{tabular}

Fonte: Quadros dos anexos I e II e cálculos dos autores.

As determinantes do comportamento eleitoral que identificámos nos pontos anteriores foram :

- a componente de longo prazo - o Kaabu,

- a componente de médio prazo - a luta pela independência,

- a componente estrutural da unidade - as etnias,

- o objectivo de desenvolvimento,

- o objectivo da paz.

O primeiro tem importância para o voto de equilíbrio entre os dois grandes grupos que combateram pelo domínio do território de que o país fazia parte. $\mathrm{O}$ candidato que consegue transmitir a mensagem de saber melhor manter esse equilíbrio é Nino Vieira. Não só porque não faz parte das etnias principais envolvidas nessa guerra, não estando por isso sujeito a apreciações com origem em costumes e hierarquias históricas ou étnicas, mas também porque, em alturas em que exerceu poder, soube distribuir cargos contemplando os dois lados dessa contenda histórica.

Quanto ao segundo critério, mais uma vez Nino Vieira capitaliza melhor do que os dois restantes candidatos a luta pela independência e a afirmação do domínio guineense no país em 1980. E se Malam Bacai Sanhá e Koumba Yalá também se podem reclamar dessa herança, não conseguem atingir os níveis de identificação de Nino Vieira junto do eleitorado para quem esse critério é importante. 
Quanto ao critério étnico, os analistas guineenses atribuem a Koumba Yalá a maior capacidade de mobilizar eleitorado segundo esse critério, excepto no que respeita à pequena etnia papel fiel ao voto em Nino Vieira. Mas se considerarmos que nenhuma etnia na Guiné-Bissau prefaz $50 \%$ da população esse critério tem importância mas não é decisivo, excepto em votações onde os números estejam muito próximos. De qualquer forma o candidato Koumba Yalá é dos três aquele para quem os votos significativos podem ser explicados, em parte, pelo desejo da sua etnia balanta ter alguém próximo no poder.

O objectivo do desenvolvimento é o critério que coloca qualquer dos candidatos em posição muito negativa para a definição de voto, com realce para Nino Vieira que esteve mais tempo no poder e portanto tem maiores responsabilidades na degradação das condições de vida da população. Poder-se-á considerar que Malam Bacai Sanhá foi dos três candidatos aquele menos penalizado pela incapacidade de conseguir esse objectivo, dado o caos que Koumba Yalá instalou no seu tempo de exercício da presidência, depois de ter ganho em 1999 claramente por um comportamento eleitoral contra o poder do partido que não consegue desenvolver o país desde a independência. Será esse o critério que coloca Malam Bacai Sanhá em maior igualdade na disputa com Nino Vieira nas eleições de 2005.

O objectivo de manutenção da paz julgamos que é dominado pela percepção que os eleitores tenham de qual o candidato que melhor consegue estabelecer acordos com os militares no activo de não intervenção fora dos quartéis. E, mais uma vez, Nino Vieira, é o candidato mais capaz de responder a esse critério, ainda que os métodos possam ser reprovados pela sociedade civil e política.

Uma tipologia do futuro próximo pode ser definida por quatro evoluções possíveis.

O retorno...

O retorno à situação existente antes da guerra de 1998-99. Ou seja Nino Vieira voltar a ter o domínio do PAIGC com apoio de muitos militantes que actualmente estão com a direcção de Carlos Gomes Júnior. Tal situação passaria antes de mais por um processo mais ou menos violento de clarificação de poder dentro das forças armadas, com predomínio dos militares que apoiaram o actual presidente no conflito de 1998-99.

$\mathrm{O}$ apoio da comunidade internacional seria fundamental para que este retorno não se transformasse num processo de vingança, com liquidação dos adversários civis e militares. Se este processo surgir como um retorno ao passado em que o país não se desenvolveu e se viu enredado em conspirações e potenciais golpes de Estado, a motivação da população para rectificar o voto nas próximas eleições será para outro candidato. Se surgir como um processo de renovação de perspectivas futuras e afirmação do país perante os seus pares sobretudo africanos e na CPLP, poderemos ter um cenário de estabilidade.

... a estabilidade...

Onde o Presidente eleito acorda um governo com o Partido maioritário no Parlamento - o PAIGC - ou com uma coligação de partidos parlamentares, seja qual for a evolução de tendências dentro dos mesmos, e consegue que os militares se mantenham nos quartéis. A normalidade dos períodos eleitorais, as 
verbas da Comunidade Internacional, o perdão da divida externa no âmbito da iniciativa HIPG e de acordos bilaterais, para ajuda ao desenvolvimento, influenciariam o voto no sentido de o actual presidente cumprir pelo menos mais um mandato.

Caberá neste cenário a capacidade ou incapacidade do Presidente eleito para manejar estratégias e instrumentos na "gestão das personalidades e interesses ", não só dos que representam os poderes já instituídos que o confrontou nas urnas, mas principalmente, os que apoiaram a sua eleição em troca de compensações (membros de sectores bastantes díspares da vida política guineense e, sem menosprezo, aos que externamente financiaram a sua candidatura ao nível sub regional e ainda Portugal e França).

Nino Vieira justificaria deste modo muitos dos elementos que apontámos como motivação eleitoral para o voto que recebeu.

\section{... a instabilidade controlada...}

Se o Presidente conseguir um compromisso PAIGC + PRS para formar governo de membros desses partidos ou de personalidades indicadas pelo próprio Presidente, terá uma governação instável e que durará, por certo, menos tempo que a legislatura. Neste cenário o parlamento teria um comportamento de fachada pois as decisões seriam sempre tomadas entre as direcções partidárias, o primeiro ministro próximo do Presidente e o próprio. Se a este acordo for acrescentado um compromisso de paz com as chefias militares, teremos uma posição dúbia da comunidade internacional, com os dois únicos países que têm interesses na área - França e Portugal - a manterem a sua presença na cooperação mas com os restantes e as organizações multilaterais a libertarem verbas de ajuda ao desenvolvimento sempre em processos de curto prazo, sujeitos em cada momento à suspensão pela evolução da estabilidade social e política. Tal cenário determinaria que o comportamento eleitoral aumentasse a volatilidade podendo com facilidade os eleitores votarem em personalidades oriundas da sociedade civil não partidária, que conseguissem transmitir a imagem de serem capazes de criar um nível de desenvolvimento e paz maior.

\section{..o caos suicidário?}

Se o presidente não conseguir qualquer acordo com o PAIGG e formar um governo de sua iniciativa, tornando o Parlamento irrelevante, e governando com base num acordo com as chefias militares, terá a comunidade internacional ausente (com excepção da França e de Portugal), uma sociedade civil a desenvolver cada vez mais processos de autonomia em relação ao Estado, e um falhanço nos processos de desenvolvimento.

Neste cenário as receitas do Estado são uma incógnita, pela retracção da Comunidade Internacional, aumentando a instabilidade e a vulnerabilidade do poder guineense face aos interesses internacionais de tráfico de drogas e de armamento.

Tal cenário levará a uma degradação gradual das instituições, golpes de Estado mais ou menos conflituosos, e à suspensão de eleições legislativas (ou à sua realização fraudulenta), mesmo se o presidente conseguir aliciar um partido para o 
apoiar, pois uma participação eleitoral muito alta torna o comportamento eleitoral difícil de influenciar por expedientes ou medidas pontuais.

Dezembro 2005, Março 2007

Carlos SANGREMAN

Universidade de Aveiro

e Instituto Superior de Economia e Gestão

Centro de Estudos sobre África e do Desenvolvimento, Lisboa

Fernando SOUSA JÚNIOR

Ministério do Trabalho e Solidariedade Social

Gabinete para a Cooperação, Lisboa

Guilherme RODRIGUES ZEVERINO

Ministério dos Negócios Estrangeiros

Instituto Português de Apoio ao Desenvolvimento, Lisboa

Miguel José de BARROS

Instituto Superior de Ciências do Trabalho e Empresa, Lisboa

\section{Addendum}

\section{O futuro próximo}

Passados um pouco mais de dois anos da redacção deste texto, dez do início do conflito armado de 1998 e cerca de dois e meio sobre a realização das últimos eleições, vamos, brevemente, tentar perceber como é que os cenários traçados anteriormente se desenvolveram ${ }^{29}$.

Numa primeira fase o processo político da Guiné-Bissau pós eleições de 2005 desenvolveu-se de acordo com o previsto naquilo que podemos considerar um misto entre o ultimo cenário - o caos suicidário - e aquele que apelidámos de « a instabilidade controlada ». Em clara ruptura entre Nino Vieira e Carlos Gomes Júnior, uma moção de censura deu a justificação ao presidente para demitir o Governo do PAIGG e formar outro com base numa coligação parlamentar entre o Fórum de Convergência para o Desenvolvimento (FCD) e membros do PAIGG dissidentes da direcção em exercício, o PRS de Koumba Yalá e o PUSD de Francisco Fadul. O Presidente assumiu a nomeação de um governo assente nessa base parlamentar e com um Primeiro Ministro de sua confiança, Aristides Gomes.

A comunidade internacional, tal como previsto nos cenários apresentados, retraiu-se na disponibilização efectiva de fundos, mantendo na agenda a intenção

${ }^{29}$ As fontes são fundamentalmente os jornais nacionais, os documentos oficiais produzidos seja por entidades guineenses seja pelas organizações internacionais multilaterais. $\mathrm{O}$ trabalho de investigação feito por Jorge Cruz na sua tese de mestrado sobre a ética da governação guineense e uma visita a Bissau em Novembro de 2007 para efectuar entrevistas para um projecto de investigação no âmbito da cooperação descentralizada, proporcionaram algumas conversas que ajudaram também a perceber a evolução da situação (CRUZ 2007). 
de realizar uma conferência de doadores mas protelando a sua concretização ${ }^{30}$, e com o FMI e BM a cortarem formalmente as relações com o país.

Se este cenário causaria inevitáveis dificuldades financeiras ao Governo, outros factos agravaram a situação :

- a instabilidade dentro do PAIGG com um conflito permanente entre militantes que querem uma aliança com o Presidente (organizados num « Movimento Abel Djassi » dentro do partido) e aqueles que só admitem esse caminho se a formação do Governo respeitar a hierarquia partidária com origem nos resultados eleitorais ;

- as noticias repetidas ${ }^{31}$ sobre o transito de droga no país em direcção à Europa com cumplicidade das forças armadas e de membros do Governo ${ }^{32}$;

- a incapacidade manifesta de governar de forma credível pelos critérios das organizações internacionais e da União Europeia $^{33}$.

Esses factores originaram uma alteração na coligação parlamentar, que se refez com base no PAIGG (e não em dissidentes), PRS e PUSD (agora sem o seu líder fundador Francisco Fadul que, não tendo sido eleito deputado, se incompatibilizou com os restantes membros da direcção e fundou um novo partido), aprovou uma moção de censura e apresentou um nome - vice-presidente do PAIGC - para Primeiro Ministro que o presidente aceitou em Maio de 2007.

Assim a situação politica do país passou a desenvolver-se de acordo com o cenário « estabilidade », assistiu-se à abertura da primeira embaixada de Angola em Bissau, com este país a assumir uma cooperação nas áreas da comunicação e da segurança como nunca tinha feito, o FMI e o Banco Mundial retomaram as missões em Maio de 2007 depois de sete anos de interrupção, a União Europeia renovou o acordo de pescas no mesmo mês, o PNUD elaborou um relatório muito favorável sobre as reformas politicas no país. O último relatório do Secretário Geral das Nações Unidas ao Conselho de Segurança, de Dezembro de 2007 referiyu que o país conseguiu «avanços significativos face aos grandes desafios », etc.

As relações do presidente com as chefias militares não foram pacíficas. $\mathrm{O}$ assassínio, em Janeiro de 2007, de um ex-membro da Junta Militar vitoriosa no conflito de 1998-99, comodoro Lamine Sanha ${ }^{34}$, por desconhecidos, levou a várias acusações de implicação do presidente Nino Vieira por parte do Presidente do PAIGC nunca provadas. Mas a evolução da relação com Batista Tagma Na Waie, Comandante chefe do Estado Maior General das Forças Armadas desde 2005,

${ }^{30}$ Veio a realizar-se em Dezembro de 2006, mas a disponibilização de fundos não seria feita antes do novo Governo tomar posse.

31 Sobretudo após o representante da UNDOC para a África central e ocidental, António Mazzitelli, dizer que a Guiné-Bissau é um "Narco-Estado nascente" (entrevista à Gazeta de Notícias, de 8 de Fevereiro de 2007).

32 Membros do Governo são, além de acusações de gestão danosa pelo governo que lhe sucedeu, chamados em 2007 a depor em tribunal para esclarecerem o desaparecimento de droga apreendida, num processo pouco comum para a capacidade da justiça guineense.

33 Veja-se por exemplo a polémica entre os dois ministros das Finanças nos jornais de Maio/ Junho sobre as dividas deixadas pelo executivo de Aristides Gomes.

${ }^{34}$ O terceiro, depois de Ansumane Mané (2000) e Veríssimo SEabra (2004). 
ex-comandante militar da Junta Militar e chefe operacional reconhecido pela tropa, provou mais uma vez o que atrás se refere da capacidade de Nino Vieira lidar com as chefias militares. O conflito recente entre Tagma Na Waie e um recente « Movimento da Sociedade Civil para Paz Democracia e Desenvolvimento », cujo primeiro congresso se desenrolou em Fevereiro de 2006, expresso em cartas publicadas nos jornais de um e outro lado, dizem-nos todavia que há alguma fragilidade numa chefia que se expõe à opinião pública da forma referida, prefigurando que a estabilidade da relação entre os militares e os restantes centros de poder politico ainda está a definir-se, apesar das declarações do presidente da Comissão de Reconciliação das Forças Armadas criada pelo próprio CEMGFA Tagma Na Waie em Janeiro de 2005 e dos apelos do Presidente a uma amnista geral. Igualmente se irá clarificar as relações de força dentro do PAIGG com o congresso marcado para Abril de 2008.

De referir por último que dos protagonistas principais da disputa eleitoral, dois deles passaram largo tempo no exterior: Malan Bacá Sanha no Senegal tendo voltado em 2007 para disputar a liderança do PAIGG (entrevista a Nô Pintcha de 31 de Maio) e Koumba Yalá ainda algures em país nunca referido, embora com intervenção concreta na direcção do PRS. 


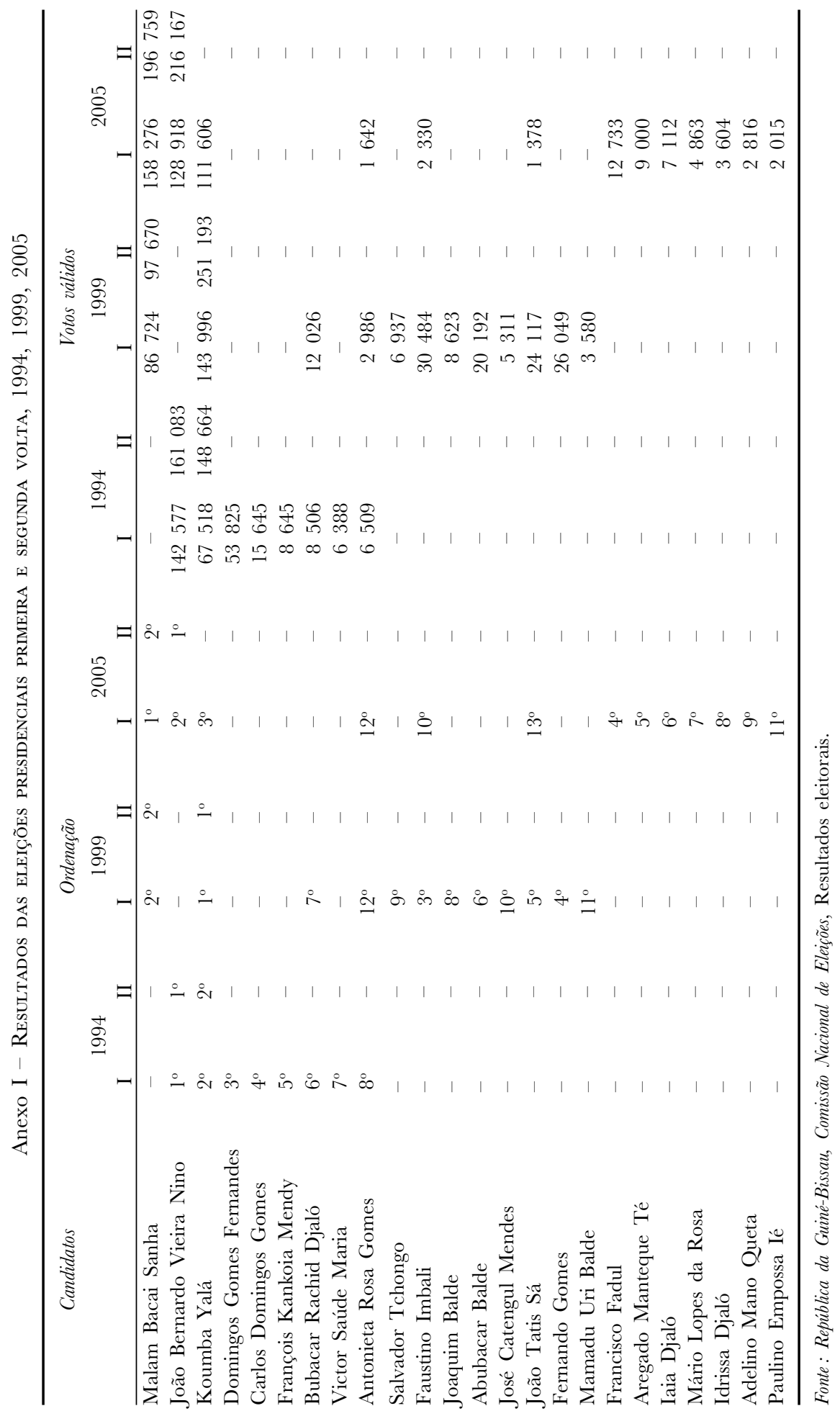


Anexo II - Resultados das Eleições POR REgiões NA SEgunda Volta 1994, 1999 E 2005

\begin{tabular}{|c|c|c|c|}
\hline & 1994 & 1999 & 2005 \\
\hline \multicolumn{4}{|c|}{ Tombali - Nalús e Balantas } \\
\hline Nino Vieira & 9510 & $\mathrm{~N}$ & 14091 \\
\hline Malam Bacai Sanhá & $\mathrm{N}$ & 7710 & 11045 \\
\hline Koumba Yalá & 12570 & 16671 & $\mathrm{n}$ \\
\hline \multicolumn{4}{|c|}{ Quinara - Balantas e Beafadas } \\
\hline Nino Vieira & 8490 & $\mathrm{~N}$ & 6608 \\
\hline Malam Bacai Sanhá & $\mathrm{N}$ & 7529 & 10437 \\
\hline Koumba Yalá & 6067 & 8059 & $\mathrm{n}$ \\
\hline \multicolumn{4}{|c|}{ Oio - Mandingas e Balantas } \\
\hline Nino Vieira & 19565 & $\mathrm{~N}$ & 27432 \\
\hline Malam Bacai Sanhá & $\mathrm{N}$ & 20772 & 31570 \\
\hline Koumba Yalá & 31843 & 40665 & $\mathrm{n}$ \\
\hline \multicolumn{4}{|c|}{ Biombo - Papeis } \\
\hline Nino Vieira & 14261 & $\mathrm{~N}$ & 24043 \\
\hline Malam Bacai Sanhá & $\mathrm{N}$ & 1559 & 3014 \\
\hline Koumba Yalá & 4771 & 17859 & $\mathrm{n}$ \\
\hline \multicolumn{4}{|c|}{ Bolama - Bijagós } \\
\hline Nino Vieira & 9925 & $\mathrm{~N}$ & 7901 \\
\hline Malam Bacai Sanhá & $\mathrm{N}$ & 2376 & 3641 \\
\hline Koumba Yalá & 878 & 5191 & \\
\hline \multicolumn{4}{|c|}{ Bafatá - Fulas e Mandingas } \\
\hline Nino Vieira & 24985 & $\mathrm{~N}$ & 28189 \\
\hline Malam Bacai Sanhá & $\mathrm{N}$ & 17751 & 28601 \\
\hline Koumba Yalá & 16740 & 30143 & $\mathrm{n}$ \\
\hline \multicolumn{4}{|c|}{ Gabú - Fulas } \\
\hline Nino Vieira & 24265 & $\mathrm{~N}$ & 29920 \\
\hline Malam Bacai Sanhá & $\mathrm{N}$ & 12235 & 28166 \\
\hline Koumba Yalá & 14236 & 29273 & $\mathrm{n}$ \\
\hline \multicolumn{4}{|c|}{ Cacheu - Manjacos } \\
\hline Nino Vieira & 13710 & $\mathrm{~N}$ & 19510 \\
\hline Malam Bacai Sanhá & $\mathrm{N}$ & 6402 & 21467 \\
\hline Koumba Yalá & 20207 & 36334 & $\mathrm{n}$ \\
\hline \multicolumn{4}{|c|}{ Bissau - Todas as etnias } \\
\hline Nino Vieira & 36372 & $\mathrm{~N}$ & 58482 \\
\hline Malam Bacai Sanhá & $\mathrm{N}$ & 21336 & 58818 \\
\hline Koumba Yalá & 41352 & 66998 & $\mathrm{n}$ \\
\hline
\end{tabular}

Fonte : Idem para os resultados para a distribuição étnica (NóBrega 2005). 


\section{Bibliografia}

Acep (Associação para a Cooperação Entre Povos) 2000, Recortes de jornais sobre o conflito de 1998/99, mimeo, Lisboa.

CAbral, A. 1974, Guiné-Bissau, nação africana forjada na luta, Porto, Afrontamento.

Carbone, G.M. 2005, Partiti politici e sistemi di partito in Africa. Temi e prospettive di ricerca, Congresso da Sociedade italiana de Ciência política, Cagliari, Milão, Università degli Studi di Milano.

CArdoso, C. 1995, «A transição democrática na Guiné-Bissau : um parto difícil », Lusotopie (Paris, Karthala).

2002, A Formação da elite política na Guiné-Bissau, Lisboa, Instituto Superior de Ciências do Trabalho e da Empresa, Centro de estudos africanos («Documento de trabalho », 5).

CARreira, A. 1969, As companhias pombalinas de navegação, comércio e tráfico de escravos entre a costa africana e o nordeste brasileiro, Bissau, Guiné-Bissau, Centro de Estudos da Guiné Portuguesa.

Chabal, P. 2002, Amílcar Cabral, Revolutionary Leadership and People's War, Londres, Hurst \& Co. [1 $1^{\text {a }}$ ed. : 1983].

Cruz, J.M.M.A.L. 2007, O Programa de Ajustamento Estrutural na República da Guiné-Bissau: uma avaliação política e ética, dissertação de mestrado, ISCTE, Lisboa.

Ferree, K. 2005, The Social Origins of Electoral Volatility in Africa, San Diego, University of California, Department of Political Science.

Koudawo, F. 1994, Eleições e lições, Bissau, Kusimon editora ("Cadernos Lus Bin »).

_ 2001, Cabo Verde e Guiné-Bissau : da democracia revolucionária à democracia liberal, Bissau, INEP («Kacu Martel », 14).

Kuenzi, M. \& Lambright, G. 2001, «Party System Institutionalization in 30 African Countries », Party Politics (Londres, Sage Publications), VII (4): 437-468.

Imbali, F. 2005, Kansaré, 30 de Maio, Bissau (entrevista).

Induta, Z. 2001, Guiné - 24 Anos de Independência (1974-1998), Lisboa, Hugin Editores.

Lopes, C. 1987, A transição histórica na Guiné-Bissau: do movimento de libertação nacional ao Estado, Bissau, IneP (« Kaçu Martel », 2).

- 1999, Kaabundé - Espaço, território e poder na Guiné-Bissau, Gâmbia e Casamance pré-coloniais, Porto, Afrontamento.

Moita, L. \& Pereira, L.T. 1976, «Guiné-Bissau : 3 anos de independência », África em Luta (Lisboa, Centro de informações e documentação Amílcar Cabral), 2.

Monteiro, A.I., ed., 1996, O Programa de ajustamento estrutural na Guiné-Bissau. Análise dos efeitos sócio-económicos, Bissau, INEP, 427 p.

Mozaffar, S. \& Scarritt, J.-R. 2005, "The Puzzle of African Party Systems », Party Politics, XI (4).

Ministério do Trabalho e Solidariedade 2001, Projecto de Desmobilização, Reinserção e Reintegração dos ex-Combatentes, Departamento de Cooperação, Lisboa.

Niane, D.T. 1989, Histoire des Mandingues de l'Ouest, Paris, Karthala-Arsan.

Nóbrega, A. 2005, O comportamento eleitoral dos islamizados da Guiné-Bissau, Lisboa, mimeo.

ONu 2004, Relatório sobre os objectivos do milénio para o desenvolvimento na Guiné-Bissau, Bissau, GuinéBissau.

2005, Relatório do desenvolvimento humano 2005, Lisboa, PNUD.

Pedersen, M.N. 1979, «Electoral Volatility », in « The Dynamics of European Party Systems: Changing Patterns of Electoral Volatility», European fournal of Political Research, (Londres, Kluwer) VII (1).

PéLissier, R. 2001, História da Guiné : Portugueses e Africanos na Senegâmbia 1841-1936, 2 vols, Lisboa, Editorial Estampa. [ed. fr. : 1989]

Rodrigues, A. Reis \& A. Silva Santos 2007, Bissau em chamas, Junho 1998, Lisboa, Casa das Letras.

Rudebeck, L. 2001, Colapso e reconstrução política na Guiné-Bissau 1998-2000, Um estudo de democratização difíill, Uppsala, Nordiska Afrikainstitutet.

Sangreman, C.S. 2003, As politicas de ajustamento e o bem-estar das famílias, na cidade de Bissau, na República da Guiné-Bissau, no periodo de 1986-2001, Tese de doutoramento, Lisboa, ISCTE. 
Sangreman, G.S. et al. 2006, A evolução politica recente na Guiné-Bissau: As eleições presidenciais de 2005 Os conflitos - $O$ desenvolvimento - A sociedade civil, Lisboa, Instituto Superior de Economia e Gestão, Centro de Estudos sobre África e do Desenvolvimento, 46 p. («Documentos de Trabalho», 70), versão on line : <http://memoria-africa.ua.pt $>$.

SAntos, M. dos 1989, «Guiné-Bissau : a formação da Nação », colóquio Inep-CodesRia-Unitar, A construção da nação e África, Os exemplos de Angola, Cabo Verde, Guiné-Bissau, Moçambique e São Tomé e Principe, Bissau.

Soronda 2000, Bissau, Inep, numero especial « 7 de Junho », Dezembro.

Touraine, A. 1965, Sociologie de l'action, Paris, Le Seuil.

Van der Drift, R. 1999, «Democracy: War and Legitimacy in Guinea-Bissau », Lusotopie (Paris, Karthala), VI : 225-240.

YaLÁ, K. 2003, Os pensamentos políticos e filosóficos, Bissau, Editora Escolar.

Zeverino, G. 2005, O conflito político-militar na Guiné-Bissau (1998-1999), Lisboa, Instituto português de apoio ao desenvolvimento (IPAD).

\section{Lista de pessoas entrevistadas}

- Alamara N' Hassé, Presidente eleito do Partido da Renovação Social (PRS)

- Alfa Balde, Vice presidente do Partido Socialista do Trabalho (PST), Secretário de Estado

- Amine Saad, Presidente do Partido União para a Mudança (UM)

- António Artur Sanha, Primeiro Ministro, Partido da Renovação Social (PRS)

- Armindo Handen, União para a Mudança (UM)

- Augusta Henriques, ONG Tiniguena

- Batista Sanca, Encarregado de Programa do PNud

- Braima Sambu, ONG AIFA PALOP

- Nelvina Barreto Gomes, Partido da Unidade Nacional (PUN)

- Carlos Gomes Júnior, Presidente do Partido da Independência da Guiné e Cabo Verde (PAIGC)

- Carlos Pinto Pereira, Conselheiro especial do Presidente da República

- Carlos Schwartz, Partido Unido Social Democrata (PUSD) e presidente da ONG AD

- Francisco Fadul Presidente do Partido Unido Social Democrata (PUSD)

- Iancuba Indjai, Presidente do Partido Socialista do Trabalho (PST), Vice Presidente do Conselho Nacional de Transição e presidente da ONG AIFA PALOP

- Jorge Jacob de Carvalho, Embaixador de Portugal

- Mamadou Jao, Director do Instituto Nacional de Estudos e Pesquisa, IneP (entrevista em Lisboa)

- Martim Maya, Representante Adjunto do PNud

- Nelo Regala, União para a Mudança (UM)

- Nelson Lopes, ONG RENAJ

- Rui de Araújo, Responsável pelas Relações Internacionais do Partido da Independência da Guiné e Cabo Verde (PAIGC)

- Silvestre Alves, Presidente do Partido Movimento Democrático Guineense

- Tomane Camará, PUSD e ONG AD

- Victor Mandinga, Presidente do Partido Plataforma Unida

Jornais guineenses consultados : Kansaré, Nô Pintcha, Gazeta de Noticias, Diário de Bissau, Baguera. 